\title{
O desenvolvimento da autocompreensão em posturas pedagógicas: explicitando o implícito entre os novos docentes'
}

Carolina Guzmán-Valenzuela"

Ronald Barnett"II

\section{Resumo}

Em sua prática docente inicial, os professores universitários geralmente vivenciam dificuldades relacionadas a como promover a aprendizagem dos alunos (por exemplo, como planejar uma aula, usar os recursos pedagógicos e avaliar a aprendizagem). A maneira como os novos professores enfrentam e abordam essas dificuldades afeta a evolução de suas carreiras acadêmicas e o modo como eles usam diversos referenciais para refletir sobre suas práticas de ensino. Levando em conta que algumas dessas dificuldades ainda não são suficientemente compreendidas, este trabalho tem por objetivo analisá-las por meio de uma abordagem qualitativa. Para tanto, foram adotadas várias técnicas de coleta de dados e fontes (professores, estudantes e pesquisadora) ao longo de um ano letivo. Os resultados evidenciam as dificuldades explícitas reconhecidas pelos docentes em relação ao seu ensino. Além disso, os dados apontaram também para as dificuldades que permaneceram implícitas, sugerindo que elas podem ser particularmente resistentes à autocompreensão, pois estão relacionadas ao desejo interior dos docentes de ordem e previsibilidade em seu ensino. 0 artigo conclui sugerindo possíveis formas de melhorar tais pressupostos implícitos.

\section{Palavras-chave}

Novos docentes - Práticas de ensino - Dificuldades implícitas e explícitas - Pesquisa qualitativa.

I- Agradecemos às docentes que participaram desta pesquisa.

II- Universidad de Valparaíso,

Valparaíso, Chile.

Contato: carolina.guzman@uv.cl

III- University of London, Londres, Reino Unido.

Contato: r.barnett@ioe.ac.uk 


\section{Developing self-understanding in pedagogical stances: making explicit the implicit among new lecturers}

Carolina Guzmán-Valenzuela"

Ronald Barnett"II

\footnotetext{
I- Acknowledgments: We wish to thank the lecturers who participate in this research.

II- Universidad de Valparaíso, Valparaíso, Chile.

Contact: carolina.guzman@uv.cl

III- University of London, London, UK.
} Contact: r.barnett@ioe.ac.uk

\begin{abstract}
In their early teaching practice, university lecturers usually experience difficulties related to how to promote learning among students (e.g., how to plan a lesson, how to use pedagogical resources, and how to assess learning). The way in which new lecturers confront and address these difficulties impacts the evolution of their academic careers and how they use diverse frameworks to reflect on their teaching practices. Taking into account that some of these difficulties are not sufficiently understood yet, this paper aims to analyze them using a qualitative approach. This study adopted several data collection techniques and sources (teachers, students, and researcher) during a single academic year. The results underscored explicit difficulties recognized by the lecturers in relation to their teaching. However, this study's data pointed also to difficulties that remained implicit, and the results suggested that these implicit difficulties may be particularly resistant to self-understanding because they are related to lecturers' inner desire for order and predictability in their teaching. The paper concludes by suggesting possible ways of ameliorating such implicit presuppositions.
\end{abstract}

\section{Keywords}

New lecturers - Teaching practices - Implicit/explicit difficulties Qualitative research. 
Ensinar em uma universidade implica um conjunto de tarefas complexo, ambíguo e - para cada professor - um tanto idiossincrático. Talvez seja razoavelmente fácil identificar o que ensinar (o conhecimento e as habilidades esperadas dos alunos), mas o mais problemático é o como ensinar para promover a aprendizagem profunda entre os alunos com diferentes backgrounds. Esse conjunto de tarefas torna-se mais difícil quando o papel do acadêmico envolve outros afazeres demorados e exigentes, como a pesquisa e a publicação (KNIGHT, 2006). Além disso, o trabalho dos acadêmicos é desenvolvido em um ambiente organizacional balcanizado (HARGREAVES, 2005), onde existe pouco trabalho colaborativo e onde os acadêmicos competem individualmente por melhores situações de ensino, por maiores salários ou por recursos para realizar pesquisas.

Esses desafios podem provocar ansiedade ou desorientação e até mesmo a saída da academia, especialmente quando novos professores - com menos de cinco anos de experiência de ensino (BOICE, 2000) - lutam para sobreviver na universidade. A maneira como os novos professores enfrentam e abordam tais difıculdades e desafios impacta a evolução de suas carreiras (MARCELO, 2009), a construção de suas identidades acadêmicas (FEIXAS, 2002b) e o modo como eles usam diversos referenciais teóricos para refletir sobre suas práticas de ensino. Este artigo concentra-se no último desses aspectos dos desafios do ensino, ou seja, em compreender como os novos docentes entendem suas práticas de ensino, as dificuldades que enfrentam no ensino e - à luz dessa evidência - as formas de melhorar as práticas de ensino e, portanto, a aprendizagem dos alunos.

\section{Referencial teórico}

Os desafios que os novos professores enfrentam afetam não só sua vida profissional como acadêmicos, mas também sua estabilidade pessoal e emocional, podendo até mesmo levar alguns a abandonarem a profissão (FEIXAS, 2002a; TARDIFF, 2004). Algumas dessas dificuldades estão ligadas ao desenvolvimento de sua identidade acadêmica, às relações hierárquicas e normativas com os colegas e ao conhecimento do ambiente organizacional (MARCELO, 1999). Outras estão relacionadas às condições de trabalho instáveis que pressionam os professores para demonstrarem sua produtividade, por exemplo, gerando renda por meio de projetos de pesquisa e trabalhos editoriais em revistas altamente classificadas (KNIGHT, 2006).

Um dos principais desafios que os novos professores universitários enfrentam diz respeito às suas práticas de ensino (MAYOR RUIZ, 2008): como dar uma aula ou como preparar um tutorial, como escolher os principais objetivos de uma aula, como planejar e organizar os conteúdos, como escolher os melhores recursos pedagógicos para ensinar determinados temas, como motivar os alunos e como avaliar sua aprendizagem (COLÉN et al., 2000; FEIXAS, 2002a; ATKINSON, 2002). De acordo com Bernstein (1996), poderíamos chamar isso de recontextualização pedagógica de um tema (o que é, em si, uma recontextualização de uma disciplina). Esse é um conjunto de desafios específicos em sua intensidade e severidade, pois normalmente as universidades gozam de um elevado grau de autonomia e, por isso, os professores não estão nem seguindo um currículo prescrito, nem tendo que adotar uma abordagem pedagógica específica. Ambas essas tarefas de ensino - a concepção de um currículo e a determinação das formas reais de ensinar um assunto - recaem sobre os ombros dos professores individualmente.

Portanto, não surpreende que os professores se sintam inseguros ao ensinar e que, muitas vezes, suas aulas sejam caracterizadas pela transmissão de grandes quantidades de informação que podem oprimir os alunos (porque os docentes podem encontrar um grau de familiaridade e segurança no conteúdo de suas disciplinas). Eles também costumam evitar as complexas questões levantadas pelos alunos e, por vezes, não se sentem suficientemente 
confiantes para responder às questões com as quais não estão familiarizados (KNIGHT, 2006). Feixas (2002a) argumenta que as principais dificuldades dos novos docentes se relacionam com o gerenciamento e a explicação do conteúdo das aulas e com como motivar os alunos e ganhar o respeito deles. Além disso, outros autores (COLÉN et al., 2000) referem-se a problemas quanto a gerenciar o tempo na sala de aula e a levar em conta o conhecimento prévio dos alunos como fontes de estresse e insegurança.

Alguns outros problemas vividos pelos docentes mais novos são a coordenação e a colaboração com outros colegas, bem como a falta de apoio institucional que produz insatisfação, frustração e solidão. A falta de apoio e assistência do departamento e da universidade (por exemplo, não oferecendo cursos de desenvolvimento profissional) contribui para a desilusão dos novos professores (FEIXAS, 2002a).

Tal período de ajuste e adaptação é de vital importância para os novos docentes, pois constitui a base para a socialização profissional (KNIGHT, 2006). Durante esse período, os professores adquirem certas normas, valores e formas de relacionamento com os colegas. Há um inevitável processo de ajuste a um ambiente organizacional que afeta as percepções e os comportamentos dos professores sobre o ensino, os alunos, a universidade e sua identidade docente (FEIXAS, 2002a). Esses ajustes e as formas como os recém-chegados vivem suas horas de trabalho funcionam como referenciais interpretativos que dão sentido às suas experiências de ensino.

A partir desses referenciais, os novos docentes tentam resolver os problemas por meio de ações passíveis de reforçar tais crenças e hábitos, os quais podem, posteriormente, tornarem-se difíceis de mudar (BULLOUGH, 2000). Desse modo, os docentes que têm uma visão mais positiva do início de suas carreiras são capazes de desenvolver atribuições internas de suas experiências profissionais - sentindo suas próprias possibilidades de agência e, assim, conseguir mais controle sobre as respostas às demandas institucionais e pressões externas. Aqueles que estão menos satisfeitos com seu trabalho muitas vezes fazem atribuições externas que os levam a estar puramente sujeitos a uma situação com pouco poder quando enfrentam circunstâncias adversas (KNIGHT, 2006). Consequentemente, as formas de resolver dificuldades e as percepções e atribuições que os novos docentes formam sobre sua satisfação com o trabalho impactam a evolução de suas carreiras acadêmicas (MARCELO, 2009) e até mesmo a construção de sua identidade acadêmica (FEIXAS, 2002b).

Para resolver esses problemas, muitas universidades em todo o mundo (Reino Unido, Noruega, Finlândia, Alemanha, França, Austrália e Espanha, entre outros) instituíram a formação não obrigatória e até mesmo a formação obrigatória para os novos professores. Weimer (2001) sugere que a formação deve se concentrar não apenas em questões técnicas ou dicas para melhorar as práticas de ensino, mas também em habilidades reflexivas (FEIXAS, 2002a). Além disso, a orientação, por exemplo, é identificada como crucial por alguns autores (WEIMER, 2001; FEIXAS, 2002a).

Nesse contexto, o presente artigo explora as principais dificuldades enfrentadas pelos professores mais novos em uma universidade da Catalunha durante os primeiros cinco anos de ensino, as formas de abordá-las e até que ponto eles as enfrentaram.

\section{Método}

Esta pesquisa utiliza uma abordagem qualitativa. Os professores identificados para o estudo foram escolhidos propositadamente (PATTON, 1990) segundo dois critérios: eles deviam ser docentes novos com menos de cinco anos de experiência de ensino e vir de diferentes áreas do conhecimento.

Depois de contatar vários docentes relativamente novos que estavam participando de um curso não-obrigatório de desenvolvimento acadêmico (2003-2005) em uma universidade 
espanhola, foram selecionadas duas, que consentiram em participar da pesquisa e foram observadas ao longo de um semestre letivo. Elas voluntariamente se deixaram entrevistar e permitiram que seus alunos fossem entrevistados sobre o ambiente de ensino. Examinar em detalhes as práticas de apenas duas docentes, como estudos de caso (STAKE, 2005), permitiu a exploração da particularidade e da riqueza desses casos (situados em seus contextos institucionais e educacionais complexos e específicos). Para tanto, a coleta de dados (fontes e técnicas) e o trabalho de campo se estenderam por um período relativamente longo de tempo (um ano letivo). As duas docentes novas são aqui chamadas ficticiamente de Anna e Blanca para preservar seu anonimato:

- Anna era uma professora associada de odontologia com quatro anos de experiência de ensino. Ela sugeriu que a observação deveria se concentrar em um curso obrigatório, porque ela estava implementando uma inovação pedagógica baseada na análise de casos clínicos (diagnóstico e tratamento clínico) em pequenos e grandes grupos de alunos. Cada sessão de ensino durou 90 minutos e foram observadas 19 sessões.

- Blanca era uma professora associada de filologia catalã, com cinco anos de experiência docente. Na universidade, ela lecionou, entre outras, várias disciplinas de catalão que foram abertas para todos os alunos, especialmente para estudantes Erasmus. A pesquisadora foi convidada a observar dois desses cursos. Cada sessão de ensino durou 120 minutos, e foram observadas 31 sessões.

Os dados foram coletados usando:

- Entrevistas em profundidade com cada professora, tanto no início quanto no final do curso (cada entrevista durou 70 minutos). Um dos objetivos dessas entrevistas foi explorar as principais dificuldades que cada docente vivenciou ao ensinar.

- Observações não-participantes de 19 sessões (professora de odontologia) e 31 sessões (professora de catalão). Nessa parte do estudo, foram utilizados registros de narrativa
(EVERTSON; GREEN, 1989), isto é, sistemas abertos, sem categorias predeterminadas, nos quais os significados são vistos como específıcos do contexto; eles incluíram grandes segmentos de texto sintetizando eventos de ensino, escritos pela observadora em linguagem cotidiana. Eles se concentraram nas potenciais dificuldades sentidas pelas professoras na condução de suas aulas. Aqui, foram observadas não só as maneiras como as professoras instruíram, mas também suas relações com os alunos. Além disso, a pesquisadora teve uma série de conversas informais com os alunos e as professoras separadamente, tanto no início quanto no final de cada aula. Essas conversas foram registradas usando-se notas de campo.

- Dois grupos focais com os alunos de Anna, que duraram 90 minutos cada, no final do semestre. Um dos temas discutidos estava relacionado com suas percepções sobre o ensino da professora.

- Três entrevistas com alunos de Blanca no final do semestre, a fim de explorar suas percepções sobre o ensino da professora. Cada entrevista durou 60 minutos.

Os dados coletados foram transcritos e as duas docentes validaram as entrevistas e observações. A análise dos dados, apoiada pelo software Atlas.ti, consistiu da leitura em profundidade de todas essas transcrições e do estabelecimento de categorias descritivas com um baixo nível de inferência. A partir das categorias descritivas, dois tipos de dificuldades surgiram (como discutiremos na seção de resultados).

\section{Observação terminológica}

Para apresentar e discutir os resultados do estudo, fazemos uma distinção significativa entre o conhecimento profissional explícito e implícito das professoras. Ao fazê-lo, estamos contrastando conhecimento explícito e implícito. A escolha do termo implícito é arbitrária, pois poderíamos muito bem empregar o termo tácito. A literatura sobre o conhecimento e a aprendizagem tácita e implícita é considerável 
e está em rápido desenvolvimento. No entanto, a distinção entre explícito e implícito não foi elucidada na literatura sobre novos docentes.

$\mathrm{Na}$ literatura mais geral, os termos implícito e tácito são usados sem delimitações claras e, às vezes, alternadamente. Um artigo de Cleeremans (1997) sobre Princípios para a aprendizagem implícita inicia seu primeiro parágrafo mencionando aprendizagem implícita, mas, em seguida, começa imediatamente o segundo parágrafo referindo-se a conhecimento tácito, sem qualquer comentário sobre esse aparente deslize de implícito para tácito. Esse é um território conceitual complexo e difuso, no qual várias dimensões estão em jogo, incluindo contextos de aprendizagem, conhecimento, comunicação, incorporação e profissionalismo. Poderíamos sugerir, por exemplo, que a tacitividade entra em jogo em situações de conhecimento incorporado, como está evidente no trabalho magistral de Polanyi (1962, 1966) sobre o conhecimento pessoal na década de 1960 e desde então usado na literatura sobre o conhecimento tácito profissional.

Para nossos propósitos, não precisamos nos aprofundar nessas questões. Preferimos realmente adotar o termo conhecimento tácito, pois queremos chamar a atenção para certas formas de conhecimento profissional dos professores, em vez de suas afırmações de conhecimento (em que a implicitude poderia ter sido um termo particularmente útil). No entanto, vamos usar conhecimento implícito, já que, em alguns setores, este parece ter se tornado mais comum e já que se convencionou diferenciá-lo da ideia de conhecimento objetivo. Para Dienes e Perner (1999, p. 752), articulando Uma teoria do conhecimento implícito e explícito, o conhecimento pode ser um objeto do representação - isto é, ele pode ser conhecimento explícito - "se os participantes podem metarrepresentar sua representação do conhecimento como tendo várias propriedades". Por outro lado, de acordo com Cleeremans (1997, p. 4), “o conhecimento é implícito quando ele pode influenciar o processamento sem possuir em si as propriedades que lhe permitiriam ser um objeto de representação”. Dada essa predisposição em favor do termo implícito em vez de tácito, adotamos aqui o termo implícito.

\section{Resultados}

Como se observa, ao coletar os dados e utilizar a triangulação de fontes (entrevistas com professores, observações e trabalho de campo na sala de aula, grupos focais com alunos), emergiu uma distinção entre dificuldades explícitas e implícitas. Levando-se em conta as definições anteriores, foram reveladas as seguintes categorias como potentes na análise dos dados:

Tabela 1 - Categorias-chave na análise dos dados coletados

\begin{tabular}{l|l}
\hline \multirow{2}{*}{ Dificuldades explícitas } & Dificuldades reconhecidas pelas \\
& docentes de modo explícito \\
\hline & Dificuldades não identificadas pelas \\
Dificuldades implícitas & docentes, mas identificadas pela \\
& pesquisadora e corroboradas pelos \\
& alunos \\
\hline
\end{tabular}

Durante as entrevistas, as docentes identificaram as seguintes dificuldades explicitas:

Tabela 2 - Dificuldades explíitas mencionadas pelas docentes durante as entrevistas

\begin{tabular}{|c|c|c|}
\hline Código & $\begin{array}{l}\text { Anna } \\
\text { (Odontologia) }\end{array}$ & $\begin{array}{l}\text { Blanca } \\
\text { (Catalão) }\end{array}$ \\
\hline $\begin{array}{l}\text { Dificuldades para ensinar alguns } \\
\text { conteúdos/assuntos }\end{array}$ & 3 & - \\
\hline Dificuldades para avaliar aprendizagem & 6 & - \\
\hline $\begin{array}{l}\text { Dificuldades para explicar um conceito } \\
\text { ou uma ideia }\end{array}$ & 3 & - \\
\hline Dificuldades para planejar uma aula & 11 & 3 \\
\hline $\begin{array}{l}\text { Dificuldades para ligar os conteúdos ao } \\
\text { cotidiano dos alunos }\end{array}$ & - & 9 \\
\hline $\begin{array}{l}\text { Dificuldades para administrar o tempo } \\
\text { durante a aula }\end{array}$ & - & 6 \\
\hline
\end{tabular}

Fonte: Dados da pesquisa. 
Por meio de conversas informais com ambas as docentes e seus alunos, e a partir das muitas observações, a pesquisadora identificou algumas outras - e diferentes - dificuldades que foram corroboradas pelos alunos. A elas nós denominamos dificuldades implícitas, as quais assumiram as formas apresentadas na tabela 3.

Tabela 3 - Dificuldades implícitas detectadas pela pesquisadora e corroboradas pelos alunos

\begin{tabular}{l|c|c}
\hline \multicolumn{1}{c}{ Anna } & $\vdots$ & \multicolumn{1}{c}{ Blanca } \\
\hline \multicolumn{2}{c}{ Subcategorias e suas frequências } \\
\hline $\begin{array}{l}\text { Dificuldades para } \\
\text { lidar com alunos com } \\
\text { dificuldades especiais }\end{array}$ & $\begin{array}{l}\text { Dificuldades para perceber } \\
\vdots \text { informação no contexto }\end{array}$ & \\
\hline Faltagógico (comportamento dos & 21 \\
ao ensinar alguns & 16 & \\
conteúdos & $\vdots$ & \\
\hline
\end{tabular}

Fonte: Dados da pesquisa.

As seções a seguir referem-se a ambos os tipos de dificuldades: as reconhecidas (explícitas) e as não totalmente reconhecidas (implícitas) pelos docentes. As partes em itálico são trechos literais das diversas técnicas de coleta de dados (isto é, entrevistas, observações, notas de campo e grupos focais). Tais trechos foram traduzidos do espanhol e do catalão para o inglês. ${ }^{1}$

\section{Dificuldades explícitas: Anna (odontologia)}

As preocupações explícitas de Anna eram tanto as de planejar uma lição e gerenciar o tempo durante a aula, colocando em prática uma nova metodologia de ensino (com base em análises de casos), quanto a avaliação da aprendizagem. Ela ainda admitiu, em várias ocasiões, que tinha problemas para equilibrar os conteúdos e para vincular os seminários teóricos com a prática clínica, sendo que esta última também implicava o desafio da coordenação com outros professores que supervisionavam tais práticas.

1- N.T.: E, em seguida, para o português.
Uma das principais preocupações de Anna era o planejamento de aulas. Ela planejava as aulas minuciosamente, mas muitas vezes deixava o planejamento para um momento posterior (pouco antes de ensinar) e injetava outros objetivos e atividades. Em uma conversa após a aula, ela observou: "Eu planejei as atividades hoje às 6:30 da manhã, e é por isso que não foi muito bem... Muitas coisas para fazer em pouco tempo...”.

A necessidade sentida por ela de planejar a aula em grande detalhe pode ser analisada como uma necessidade de ter a aula sob controle - em termos de saber exatamente o que e como ensinar, uma dificuldade típica vivida por novos docentes (FEIXAS, 2002b; ATKINSON, 2002).

Outro desafio mencionado por Anna era o de explicar certos temas para serem compreendidos pelos alunos, como ela admitiu em uma entrevista:

Eu não me expresso bem em público, e sinto que estou perdendo alguns tópicos. Eu não falo bem, não sei como explicar algumas ideias ou conceitos que eu conheço muito bem para os alunos. Isto é um pouco difícil para mim.

Esse trecho é particularmente interessante porque o problema não é apenas saber determinados temas, mas também explicá-los de uma forma que os torne compreensiveis para os alunos. Vemos aqui um autorreconhecimento de uma dificuldade sentida na transformação de um tópico em um conjunto compreensível de unidades de aprendizagem, ou seja, o know-how do ensino ou, como Shulman (1986) o chama, o conhecimento do conteúdo pedagógico do professor.

Outra dificuldade identificada por Anna era que ela não conseguia ter certeza se a análise de casos clínicos (como recurso pedagógico) estava favorecendo a aprendizagem independente e significativa dos alunos:

Eu sei que eles tentam aprender, eles tentam, sim, mas não sei se eles alcançam 
esse objetivo usando essa nova metodologia de análise de casos clínicos. Eles têm que trabalhar duro por si mesmos resolvendo um problema... É uma tarefa difícil para eles.

\section{Dificuldades explícitas: Blanca (língua catalã)}

Blanca comentou que, quando ingressou na universidade, estava preocupada com seu ensino e tinha dúvidas sobre quase tudo. Ela se sentia insegura no planejamento de aulas e no gerenciamento do tempo. Ela não sabia como encher uma aula de duas horas com atividades suficientes. Por causa disso, costumava planejar as aulas e o tempo minuciosamente. No entanto, na maioria das vezes, ela não seguia esse planejamento, porque, conforme ela disse em uma entrevista, "cada grupo tem o seu próprio ritmo". Como resultado, as atividades realizadas com os alunos podem ser diferentes de um grupo para outro:

Quando você começa, Jesus, uma aula de duas horas! Uma eternidade, certo? Depois, você percebe que uma aula de língua não pode durar menos de duas horas, mas essa consciência vem depois... Eu costumava sequenciar tudo com tempo (esta atividade terá 10 minutos, a outra 15 etc.) Mas, claro, isso não funcionava o tempo todo, pois cada grupo tem seu próprio ritmo, sua própria maneira; há assuntos que são mais difíceis para alguns grupos.

Simultaneamente, ela também teve dificuldades quando preparava uma aula com tantas atividades que ela não era capaz de cobrir em profundidade. No entanto, sua principal preocupação, no momento da pesquisa, tinha a ver com permitir que os estudantes vissem as ligações entre sua experiência no curso e seus contextos diários e suas vidas. Blanca tinha um objetivo de ensino a longo prazo: incorporar a forma catalã de ser à vida pessoal dos alunos. Ela se sentia frustrada quando percebia que não estava alcançando esse objetivo. Em uma conversa após uma aula, ela exclamou: "Olha só eles falando... A aula terminou e eles estão falando em espanhol. [...] Eles estão perdendo a oportunidade de praticar o catalão!”.

\section{Dificuldades implícitas: Anna e Blanca}

Loughran (2006) sugere que os professores prestem atenção ao que eles consideram ser problemático. Essa concepção de problemas implica que eles são relativos: uma situação que poderia ser problemática para um professor pode não ser para outro. Em outras palavras, um problema deve ser autorrepresentado para se tornar uma dificuldade explícita. Além disso, a percepção de uma situação considerada problemática depende de vários fatores, tais como as expectativas e convicções do professor, o estágio de sua carreira, os alunos. a sala de aula e os contextos institucionais.

Várias situações durante as aulas foram interpretadas como problemáticas pela observadora, mas não plenamente interpretadas como tal por nenhuma das duas docentes - uma ocorrência típica com novos professores, de acordo com Berliner (1988). Para ambas as professoras, essas dificuldades se mostraram de diferentes maneiras, mas tiveram elementos em comum.

Durante as aulas de Anna (de odontologia), por exemplo, a participação dos alunos foi elevada e permanente. No entanto, uma aluna estrangeira, estudando através do programa europeu Erasmus, teve dificuldades de acompanhar as aulas, porque não compreendia suficientemente a língua (catalão), apesar de dominar espanhol. Esse problema foi mencionado para Anna por um de seus colegas. Posteriormente, Anna tentou dar sua aula em espanhol, mas, depois de algumas tentativas, ela não conseguiu falar efetivamente em espanhol e continuou suas aulas em catalão. Como resultado, alguns alunos ajudaram a estudante estrangeira, traduzindo partes das aulas, uma tarefa difícil, pois as aulas exigiam muita atenção para resolver os casos clínicos. Nas discussões pós-sessão entre Anna e a pesquisadora, esse 
problema, observado em várias ocasiões, foi mencionado para Anna. Após a primeira aula, Anna realmente conversou com a aluna para verificar se ela tinha conseguido acompanhar. Parecia que o problema havia sido resolvido. No entanto, durante uma das aulas, a aluna estrangeira comentou com seus colegas que ela ainda estava tendo problemas sérios. Essa informação foi retransmitida para Anna, que pareceu surpresa durante a discussão posterior:

Eu disse à Anna que a estudante francesa não estava acompanhando a lição. Anna pareceu chateada e ela disse que já tinha perguntado a essa aluna muitas vezes se ela estava entendendo as aulas, e ela tinha respondido "sim". Ela acrescentou que teria que falar com a aluna novamente sobre esse assunto. Ela pareceu chateada.

Embora Anna tenha percebido essa situação como problemática desde o início do semestre e já tivesse tentado diferentes abordagens, ela chegou a um ponto em que não fez mais nada para resolvê-la. Ela não investiu mais atenção e energia depois de algumas aulas porque, segundo ela, "tinha feito tudo o que era humanamente possível para resolver o problema". Ela também comentou que tinha notado a falta de interesse da aluna. Portanto, Anna representou o assunto para si mesma como um problema que não era mais seu. No final, a aluna começou a faltar às aulas e não terminou o semestre.

De acordo com Knowles, Cole e Presswood (1994), muitos professores iniciantes não são treinados para lidar com a diversidade de alunos. Alguns não conseguem satisfazer necessidades múltiplas de uma forma que incentive o interesse dos alunos, embora as professoras pudessem reconhecer e identificar as diferenças individuais (BULLOUGH, 2000). Anna sabia que tinha de considerar as necessidades dos estudantes estrangeiros, mas ela parecia não saber como lidar com eles. A capacidade de tomar decisões num contexto de aprendizagem específico e com alunos específicos depende de sabedoria prática ou de um conhecimento intuitivo enraizado na experiência (ATKINSON, 2002). Lidar com situações problemáticas é possível se o professor tiver desenvolvido referenciais oportunos e úteis para a compreensão do que está acontecendo na sala de aula e para saber como lidar com uma situação problemática específica do contexto. Os novos docentes, como Anna, muitas vezes não têm tanta sabedoria prática.

No caso de Blanca (a professora de filologia), a pesquisadora detectou uma situação problemática ligada às interações entre a professora e seus alunos. Embora a atmosfera da sala de aula fosse marcada por um tratamento cordial e respeitoso, também foi caracterizada por pouca participação dos alunos. Uma estudante explicou que a quantidade excessiva de exercícios de gramática não estava conseguindo envolver os alunos:

Eu acho que as lições, às vezes, eram um pouco chatas, com tantos exercícios de gramática. Se eu fosse a professora, perceberia que ninguém estava participando.

Além disso, a relação entre a professora e seus alunos foi um pouco distante. De certa forma, Blanca parecia emocionalmente desconectada de alguns alunos, sobretudo os mais silenciosos que não participavam durante a aula e que não pareciam motivados pelo assunto. Durante as observações, alguns silêncios constrangedores e longos foram detectados pela observadora, mas estes pareciam não ser percebidos por Blanca.

Entre os aspectos que perturbavam as aulas estava o fato de que vários alunos chegavam tarde ou saíam mais cedo, o que visivelmente afetava a continuidade da aula, causando desânimo e irritação em Blanca. A situação foi confırmada por um dos alunos em uma entrevista:

Ah, é como dizer "Oi, eu cheguei, mas não quero estar aqui". Eu realmente acho que havia alguns colegas de classe que não queriam estar ali. 
No entanto, a baixa participação parecia se dissipar quando Blanca orquestrava atividades como discussões sobre notícias, sobre os países de origem dos alunos ou sobre turismo. Isso incluía atividades que demandavam o envolvimento dos alunos devido à novidade dos assuntos, aos trabalhos em pequenos grupos ou aos métodos interativos (por exemplo, competições, testes, elaboração de material escrito).

Tais ocasiões levantaram a questão de saber se Blanca poderia ler os sinais de comportamento dos alunos que são capazes de orientar sua atuação docente. A situação poderia ser explicada de duas maneiras: ou ela não percebia esses sinais, pois estava focada no conteúdo das aulas e em como organizá-lo, ou ela os percebia sim, mas não sabia como lidar com o problema. Durante uma entrevista, as palavras de Blanca sustentaram a hipótese de que, apesar de ela ver a atmosfera da sala de aula e sua interação com os alunos como relevantes, isso não era suficientemente importante para que ela modificasse sua atuação. Em outras palavras, havia uma lacuna entre a autorrevelação das professoras (o que elas disseram à pesquisadora) e sua ação na sala de aula (oferecendo, assim, um exemplo da distinção de Schön (1983) entre teoria abraçada e teoria em ação):

Na maioria das vezes, o que me perturba é a relação com os alunos, né? Às vezes, eu vejo que não estou sendo interativa... E, se um aluno é tímido, isso é um problema para mim... porque ele vai ficar perdido... Mas, para ser honesta, não sou muito focada nisso, embora eu saiba que é essencial.

Knowles, ColeePresswood (1994) indicam que, em geral, as aulas têm suas próprias regras e os professores precisam compreender essas regras e redirecionar sua atuação de acordo com o comportamento e as reações dos alunos. As aulas de Blanca eram altamente estruturadas e definidas pelo conteúdo, e aparentemente ela não estava prestando atenção suficiente à pouca participação dos alunos.
Atkinson(2002)explicaessecomportamento como uma falta de conhecimento intuitivo que poderia permitir que o professor detectasse certos padrões, como o estado de espírito da classe. Além disso, Berliner (1988) e Knight (2006) referem-se a professores proficientes e especialistas como aqueles que dominam o know how; eles são intuitivos, no sentido de que adquiriram grandes blocos de experiência e são capazes de ler os acontecimentos em sala de aula de uma forma holística, que ajuda a guiar sua atuação. Eles também conseguem prever e enfrentar situações de conflito de forma eficaz. Outros docentes, no entanto, tendem a ignorar elementos perturbadores na sala de aula (SWANSON et al., apud HOGAN; RABINOWITZ; CRAVEN, 2003).

\section{As rotinas e suas limitações}

Nas observações de sala de aula, foi possível detectar um padrão estável na forma como Anna e Blanca conduziram suas aulas. Anna (em odontologia) dedicou grande parte de sua atenção à preparação de planos de aula detalhados. Eles incluíram várias atividades a serem concluídas em 90 minutos, que resolveriam o caso clínico proposto. No entanto, algumas vezes não houve tempo suficiente para se chegar à resolução. Alguns casos foram especialmente complexos, de acordo com o que os alunos comentaram com Anna depois da aula e durante os grupos focais. 0 trecho seguinte é de um grupo focal:

Às vezes, o tempo não foi suficiente para analisar o caso em profundidade, precisamos de mais tempo para fazer isso... É uma boa ideia analisar o caso de cada aula, mas alguns casos são tão complexos que são necessárias mais aulas... E é por isso que nós temos que literalmente correr o tempo todo.

Anna parecia mais focada em manter o cronograma (as diversas atividades com seus tempos de execução, em pequenos e grandes grupos), sem perceber se era necessário um 
ajuste. Apesar de ter um plano detalhado, a professora muitas vezes enfrentava situações que não podia prever, e ela não conseguia lidar com elas (LOUGHRAN, 2006). Portanto, um plano de ensino parece apropriado em abstrato, mas, na sala de aula, ele pode precisar de alguns ajustes para atender às necessidades de aprendizagem dos alunos.

Por outro lado, Blanca (em filologia) programava suas aulas a fim de completar um grande número de exercícios gramaticais, montando aulas rotineiras e monótonas que nem sempre motivavam os alunos. Apesar disso, Blanca pouco mudou suas rotinas de exercícios. Essa situação foi apontada durante uma entrevista. Ela comentou que, embora soubesse que algumas atividades motivavam mais os alunos (conversas em grupos, por exemplo), em seu ponto de vista, os exercícios de gramática eram essenciais para promover a aprendizagem. Esse comportamento pedagógico pode ser entendido levando-se em conta as necessidades de controlar a aula e estruturar uma tarefa: quanto mais estruturada a aula, mais fácil é executá-la e mantê-la sob controle. 0 diálogo espontâneo entre os alunos é menos fácil de moderar. Aqui, na verdade, completar exercícios de gramática tinha um objetivo claro, um tempo fixo para a conclusão e respostas corretas específicas.

Assim, apesar das necessidades ou dos ritmos dos alunos, ambas as professoras conduziam suas aulas de uma forma altamente rotinizada, sem espaço para mudanças. Essas rotinas ajudaram as professoras a controlar suas aulas e a reduzir a imprevisibilidade que uma sala de aula com interações potencialmente inesperadas com os estudantes pode apresentar (KNIGHT, 2006).

Uma vez que as rotinas normalmente aparecem após uma quantidade considerável de experiência, e dado que uma experiência de ensino limitada dificilmente permite o desenvolvimento de rotinas, a rotinização das práticas de ensino poderia ser vista como especialmente problemática em novos professores. No entanto, como Kreber (2002) indicou, os professores universitários aprendem a ensinar por meio de tentativa e erro, de modo que as estratégias que funcionam são armazenadas e integradas em um repertório em desenvolvimento sentido como eficaz, sem muita autorreflexão. Tal repertório permite ao professor executar uma aula com relativa facilidade por meio de procedimentos implementados e testados no passado com bons resultados. Em ambos os casos estudados, o desenvolvimento incipiente de rotinas de ensino oferecia uma âncora, dando às duas professoras alguma estabilidade para prevenir a imprevisibilidade da sala de aula. No entanto, essas rotinas pareceram dificultar o aprendizado profundo entre os alunos, por um lado, e a motivação deles, por outro. Em outras palavras, as rotinas poderiam oferecer às professoras limites em uma situação de outra forma ilimitada, mas não necessariamente contribuir para a aprendizagem dos alunos. As novas docentes, neste estudo, não avaliaram plenamente os efeitos que suas práticas de ensino altamente delimitadas tiveram sobre os alunos.

\section{Explícito e implícito: relações difusas}

A partir dos resultados desta pesquisa, parece que, em suas situações pedagógicas, os professores de ensino superior possuem várias compreensões sobre suas qualidades e capacidades. Uma dimensão em jogo é o grau de autocompreensão do professor: até que ponto um professor tem um conhecimento consciente e autorreflexivo dos pressupostos, das atitudes e dos valores que moldam suas abordagens pedagógicas, seus comportamentos pedagógicos e suas respostas no ambiente da aula e nos encontros com seus alunos? Observamos que o professor pode também ser influenciado por compreensões e atitudes não imediatamente presentes na mente; tais compreensões préconscientes podem simplesmente não terem sido trazidas à tona por um processo de autorreflexão. Notamos também que o professor pode estar ciente de certas aspirações e certos 
valores pedagógicos, mas pode conceder-lhes uma prioridade bastante reduzida em relação a outros valores (por exemplo, querer manter a ordem pedagógica ou a estabilidade psíquica no contexto de uma potencial sobrecarga na situação pedagógica). 0 professor pode reprimir tais sentimentos e a não realização destes, por sua vez, pode causar algum desconforto.

Aparentemente, portanto, há não apenas componentes explícitos e implícitos envolvidos na autocompreensão do professor acerca de suas capacidades na sala de aula, mas - talvez especialmente no ensino superior - tais componentes explícitos e implícitos podem apresentar uma variedade de relações. Algumas dessas relações foram vistas nos dados empíricos obtidos neste estudo. Elas incluem autocompreensões que:

- São explicitamente reconhecidas e são propositadamente levadas adiante;

- São reconhecidas, mas são minimizadas; ou colocadas em uma espécie de gaveta interior, escondida da análise;

- Apresentam dificuldades tão graves que não são abordadas ou resolvidas (mesmo que parcialmente abordadas);

- Passam despercebidas, mas influenciam o repertório pedagógico do professor e, assim, permanecem implícitas;

- Surgiram ao longo do tempo como parte do repertório de um profissional habilidoso. Provavelmente em algum momento tornaram-se explícitas, mas, desde então, recuaram na visibilidade, quando sua eficácia pedagógica foi demonstrada; assim, chegaram a formar elementos testados de um repertório pedagógico internalizado.

Dessa análise, emergem duas considerações gerais imediatas. Em primeiro lugar, a distinção entre explícito e implícito aponta para um complexo de relações possíveis. É bastante inútil simplesmente sugerir que os componentes explícitos e implícitos existem no repertório de um professor, pois alguns componentes implícitos podem ser vantajosos para o ensino eficaz, ao passo que outros podem ser prejudiciais. Portanto, é necessária uma maior diferenciação. Propomos a distinção de saber se um profissional tem uma disposição de abertura ou fechamento quanto ao repertório pedagógico. Era evidente que nossos dois sujeitos tinham graus de fechamento em relação a seus repertórios pedagógicos, de modo que certos elementos de seu repertório - mesmo que tacitamente reconhecidos - permaneceram por abordar. Em outras palavras, sua autorreflexão foi truncada. Por outro lado, as compreensões dos profissionais habilidosos podem ser implícitas, mas nem sempre foram ou são passíveis de pesquisa, de análise autocrítica. Portanto, a distinção entre abertura e fechamento tem que ser pensada juntamente com as categorias explícito e implícito em qualquer exame do repertório de um professor. (Como um construto para o referencial teórico, essas duas distinções poderiam ser vistas como dois eixos formando uma grade, abrindo espaços de posições pedagógicas. Falta espaço aqui para seguir esse caminho teórico.)

Em segundo lugar, a busca de ordem pode ser muito significativa no referencial inicial do repertório pedagógico do professor, muito mais significativa, aliás, do que se tem reconhecido na literatura. Dadas as condições de complexidade inerentes à situação pedagógica, sem mencionar a supercomplexidade dos próprios conceitos $\mathrm{e}$ das responsabilidades do que é ser professor no ensino superior - uma condição absolutamente aberta e contestável (BARNETT, 2000) -, não é surpreendente que os docentes mais novos busquem alguns meios de estabilidade. Segurar-se firme a um currículo-em-prática, fortemente referenciado no conhecimento e nos conteúdos de sua disciplina, e evitar ações e considerações que estejam fora de tais intenções pedagógicas é uma abordagem compreensível e até mesmo racional do papel docente. Uma pedagogia do risco é adiada em favor de uma pedagogia da segurança.

Dessas duas considerações gerais resulta que, para o professor iniciante ou com pouca experiência, certos componentes do repertório pedagógico podem ser quase além da autocompreensão. Aqui, o quase é crucial. Parece que muitas vezes os elementos 
de fechamento nas abordagens do professor revelam um grau de resistência até mesmo à autorreflexão. Essa autorreflexão, afınal, poderia revelar a tensão com os valores abraçados pelo professor. Ou tal tensão teria de ser exposta ao self, ou elementos do repertório do professor que proporcionam estabilidade talvez tivessem que ser abandonados, potencialmente abrindo caminho para mais agitação interna.

\section{Conclusões}

A partir deste estudo, surgem algumas questões: os professores podem, por si só, chegar a uma consciência de suas dificuldades quando ensinam? Eles estão conscientes dos efeitos que seu ensino tem sobre seus alunos? Até que ponto eles poderiam estar cientes - ou tomar ciência - de seus pressupostos moldando sua orquestração das situações de ensino pelas quais eles são responsáveis? De que forma os professores poderiam ser habilitados a trabalhar com as muitas tensões internas que possam estar sentindo?

0 ensino eficaz é uma atividade específica do contexto e varia de acordo com a disciplina, os alunos, a instituição, os microssistemas e, por último, mas não menos importante, de acordo com os pressupostos e valores pedagógicos do próprio professor. Essa observação do senso comum tem duas implicações. Por um lado, as situações problemáticas não podem ser vistas como dificuldades normais, com fórmulas fixas que podem ser aplicadas para resolvê-las. Por outro lado, não apenas os novos docentes, mas também os professores universitários experientes podem enfrentar situações de conflito que, sob certas circunstâncias, podem se desenvolver e gerar tensão na sala de aula.

As docentes que participaram deste estudo vivenciaram problemas que têm sido bem documentados na literatura (COLÉN et al., 2000; KNIGHT, 2006): dificuldades no planejamento, na gestão do tempo, na avaliação da aprendizagem, na explicação de um tópico e assim por diante. Ambas as professoras, porém, tinham atingido uma fase de estabilização em suas práticas de ensino (MARCELO, 2009), achando que sabiam o que funcionava (KREBER, 2002).

No entanto, a pesquisa revelou situações problemáticas sobre as quais as docentes aparentemente não estavam plenamente conscientes ou não conceituavam de modo sério. As dificuldades detectadas foram ligadas à falta de capacidade para ler as pistas das situações de ensino e as necessidades de aprendizagem dos alunos tal como elas emergiram in situ. As docentes pareceram mais focadas em seus roteiros de ensino do que na aprendizagem de seus alunos. Esses roteiros atuaram como rotinas, permitindo que elas negociassem as demandas conflitantes que estavam enfrentando como professoras - progredindo com o assunto e possibilitando que os alunos realizassem várias tarefas e adquirissem uma série de habilidades -, mas não foram necessariamente adequados às necessidades individuais dos alunos. Muitas vezes, as duas docentes não tiveram consciência tanto de suas dificuldades ao ensinar, quanto dos efeitos que suas práticas de ensino exerceram em seus alunos. Elementos de seu ensino não apenas permaneceram escondidos de sua autoanálise, mas também haviam sido colocados em uma espécie de gaveta interna fechada, cuja abertura poderia ser problemática para elas.

Surge, então, a questão de saber se e como se pode desenvolver uma conscientização e uma orientação de ensino concentradas mais em posições de aprendizagem dos alunos. Uma resposta poderia ser a utilização de processos de reflexão sistemática sobre as práticas de ensino e de autoavaliação (ERAUT, 1999; KREBER, 2002). Reflexões deliberativas e contínuas sobre as práticas de ensino parecem ser a chave para aprender com a experiência, superar as dificuldades e, além disso, explicitar o implícito nas posturas pedagógicas dos professores. No entanto, essa estratégia não pode acontecer apenas individualmente; a 
reflexão individual deve ser complementada por outras duas fontes: os alunos (por meio de sistemas confiáveis de feedback) e os colegas (por meio de trabalho colaborativo). Os colegas, de acordo com a literatura (KNIGHT, 2006), desempenham um papel importante na socialização dos novos docentes nas universidades caracterizadas por culturas balcanizadas e trabalho isolado. Essas atividades colaborativas sistemáticas podem constituir oportunidades para compartilhar experiências de ensino de formas não ameaçadoras, especialmente tendo em vista a racionalidade que pode acompanhar tal autorrevelação pedagógica. Portanto, mecanismos formais e institucionais desenvolvidos por departamentos e faculdades para apoiar novos docentes por meio de um trabalho colaborativo podem ser cruciais (FEIXAS, 2002a; ZABALZA, 2004; KNIGHT, 2006). Disciplinas e departamentos certamente desempenhariam um papel central, uma vez que podem oferecer orientação e aconselhamento sobre questões pedagógicas de forma legítima perante os colegas em questão. Os pressupostos profissionais do professor não precisam estar além de toda autocompreensão, mas sua emergência numa pedagogia conscientemente intencional exige alguns cuidados e compreensão por parte das instituições. A partir desse tipo de apoio, pode ser possível alcançar o que Kreber (2002) chama de sabedoria de ensino. 


\section{Referências}

ATKINSON, Terry. Aprender a enseñar: habilidades intuitivas y objetividad razonada. In: ATKINSON, Terry; CLAXTON, Guy (Eds.). EI profesor intuitivo. Barcelona: Octaedro, 2002. p. 196-234.

BARNETT, Ronald. Realizing the university in an age of supercomplexity. London: Open University, 2000.

BERLINER, David. The development of expertise in pedagogy. Washington: American Association of Colleges for Teacher Education, 1988

BERNSTEIN, Basil. Pedagogy symbolic control and identity: theory, research and critique. London: Taylor and Francis, 1996.

BOICE, Robert. Advice for new faculty members. Needham Heights, MA: Allyn \& Bacon, 2000.

BULLOUGH, Robert. Convertirse en profesor: la persona y la localización social de la formación del profesorado. In: GOODSON, Ivor F.; GOOD, Thomas L.; BIDDLE, Bruce J. (Eds.). La enseñanza y los profesores I: la profesión de enseñar. Barcelona: Paidós. 2000. p. 99-116.

CLEEREMANS, Axel. Principles for implicit learning. In: BERRY, Dianne C. (Ed.). How implicit is implicit learning? Oxford: Oxford University, 1997.

COLÉN, María Teresa et al. Las necesidades formativas del profesorado universitario novel para el ejercicio de la función docente. In: Primer Congreso Internacional: docencia universitaria e innovación, 1., 2000, Barcelona. Annals... Barcelona: IUB, UAB y UPC, 2000.

DIENES, Zoltan; PERNER, Josef. A theory of implicit and explicit knowledge. Behavioral and Brain Sciences, USA, v. 22, p. 735$808,1999$.

ERAUT, Michael. Developing professional knowledge and competence. Philadelphia: Falmer, 1999.

EVERTSON, Carolyn; GREEN, Judith. La observación como indagación y método. In: WITTROCK, Merlin C. (Ed.). La investigación de la enseñanza II: métodos cualitativos y de observación. Madrid: Paidós, 1989. p. 303-421.

FEIXAS, Monica. El profesorado novel: estudio de su problemática en la Universitá Autónoma de Barcelona. Boletín RED-U, Santiago de Compostela, v. 2, n. 1, p. 33-44, 2002a.

El desenvolupament professional del professor universitari com adocent. Tese (Doutorado) - Departament de

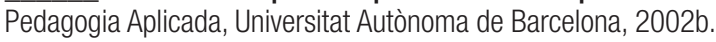

HARGREAVES, Andy. Profesorado, cultura y postmodernidad: cambian los tiempos, cambia el profesorado. 5. ed. Madrid: Morata, 2005.

HOGAN, Tracy; RABINOWITZ, Michael; CRAVEN, John. Representation in teaching: inferences from research of expert and novice teachers. Educational Psychologist, Philadelphia, v. 38, n. 4, p. 235-247, 2003.

KNIGHT, Peter. El profesorado de educación superior: formación para la excelencia. 2. ed. Madrid: Narcea, 2006.

KNOWLES, Gary; COLE, Ardra; PRESSWOOD, Colleen. Through preservice teachers's eyes: exploring field experiencias through narrative and inquiry. New York: Macmillan College, 1994.

KREBER, Caroline. Teaching excellence, teaching expertise, and the scholarship of teaching. Innovative Higher Education, New York, v. 27, n. 1, p. 5-23, 2002.

LOUGHRAN, John. Developing a pedagogy of teacher education: understanding teaching and learning about teaching. New York: Routledge, 2006.

MARCELO, Carlos. Formación del profesorado para el cambio educativo. Barcelona: EUB, 1999. 
MARCELO, Carlos (Coord.) Políticas de inserción a la docencia. In: (Ed.). El profesorado principiante: inserción a la docencia. Barcelona: Octaedro, 2009. p. 7-57.

MAYOR RUIZ, Cristina. El desafío de los profesores principiantes universitarios ante su formación. In: MARCELO, Carlos (Ed.). EI profesorado principiante: inserción a la docencia. Barcelona: Octaedro, 2008.

PATTON, Michael. Qualitative evaluation and research methods. Newbury Park, CA: Sage Publications, 1990.

POLANYI, Michael. Personal knowledge: towards a post-critical philosophy. London: Routledge and Kegan Paul, 1962.

. The tacit dimension. New York: Doubleday, 1966.

SCHÖN, Donald. The reflective practitioner: how professionals think in action. London: Temple Smith, 1983.

SHULMAN, Lee. Those who understand: knowledge growth. Educational Researcher, v. 15, n. 2, p. 4-14, feb. 1986.

STAKE, Robert. Qualitative case studies. In: DENZIN, Norman Kant; LINCOLN, Yvonna Sessions (Eds.). SAGE handbook of qualitative research. 3. ed. California: Sage, 2005. p. 443-466.

TARDIFF, Maurice. Los saberes del docente y su desarrollo profesional. Madrid: Narcea, 2004.

WEIMER, Maryellen. Learning more from the wisdom of practice. New Directions for Teaching and Learning, Wiley On line Library, v. 2001, n. 86, p. 45- 56, 4 feb. 2002.

ZABALZA, Miguel Ángel. La enseñanza universitaria: el escenario y sus protagonistas. Madrid: Narcea, 2004.

Recebido em: 27.12.2012.

Aprovado em: 24.04.2013.

Carolina Guzmán-Valenzuela é chefe do Departamento de Psicologia da Educação na Escola de Psicologia da Faculdade de Medicina da Universidade de Valparaíso, Chile. Seus interesses estão nos processos de ensino e aprendizagem em universidades e na identidade acadêmica. Atualmente leciona em programas para alunos de graduação e pós-graduação em pesquisa qualitativa na área da Educação.

Ronald Barnett é professor emérito de Ensino Superior no Instituto de Educação da Universidade de Londres, Reino Unido. Nos últimos 30 anos, vem desenvolvendo uma filosofia social da universidade e do ensino superior. Seu livro mais recente intitula-se Imagining the University e foi publicado em 2013 pela Routledge. 